\title{
Minichromosome maintenance 2 is an independent predictor of survival in patients with lung adenocarcinoma
}

\author{
HIROKI SAKAI $^{1}$, HIROYUKI KIMURA ${ }^{1}$, KANJI OTSUBO ${ }^{1}$, TOMOYUKI MIYAZAWA $^{1}$, HIDEKI MARUSHIMA ${ }^{1}$, \\ KOJI KOJIMA ${ }^{1}$, MOTOHIRO CHOSOKABE ${ }^{2}$, NAOKI FURUYA ${ }^{3}$, JUNKI KOIKE ${ }^{2}$, KIYONAGA FUJII ${ }^{4,5}$, \\ TOSHIHIDE NISHIMURA ${ }^{4}$, HARUHIKO NAKAMURA ${ }^{1,4}$ and HISASHI SAJI ${ }^{1}$
}

Departments of ${ }^{1}$ Thoracic Surgery and ${ }^{2}$ Pathology, ${ }^{3}$ Division of Respiratory Medicine, Department of Internal Medicine and ${ }^{4}$ Department of Translational Medicine Informatics, St. Marianna Medical University Hospital, Kawasaki, Kanagawa 216-8511;

${ }^{5}$ Laboratory of Analytical Chemistry, Daiichi University of Pharmacy, Fukuoka 815-8511, Japan

Received June 21, 2021; Accepted October 1, 2021

DOI: $10.3892 / \mathrm{mco} .2021 .2455$

\begin{abstract}
Minichromosome maintenance (MCM) protein deregulation is associated with tumor formation, progression and malignant transformation. MCM2 is frequently expressed during premalignant lung cell proliferation and is a sensitive marker for the early detection of pulmonary malignant lesions. The present study was undertaken to investigate whether MCM2 expression is of clinical and prognostic value in patients who have undergone lung adenocarcinoma resection. Between January 2009 and December 2010, 102 consecutive patients underwent complete pulmonary resection (involving lobectomy or more extensive resection) for lung adenocarcinoma at St. Marianna Medical University Hospital (Kanagawa, Japan). Among those, 73 patients, who had a final pathological diagnosis of lung adenocarcinoma measuring $\geq 10 \mathrm{~mm}$, were enrolled in the present study. High MCM2 expression was found in 35 patients (48.0\%). Univariate analysis of the overall survival (OS) revealed that pathological stage and MCM2 expression were significant prognostic factors in lung adenocarcinoma $(\mathrm{P}<0.001$ and $\mathrm{P}<0.002$, respectively). Univariate analysis of the recurrence-free survival (RFS), the significant prognostic factors included pathological stage, EGFR mutation status and MCM2 expression $(\mathrm{P}<0.001, \mathrm{P}<0.034$ and $\mathrm{P}<0.003$, respectively). On multivariate survival analysis, high MCM2 expression and pathological stage II-III were identified as independent strong
\end{abstract}

Correspondence to: Professor Hisashi Saji, Department of Thoracic Surgery, St. Marianna Medical University Hospital, 2-16-1 Sugao, Miyamae-ku, Kawasaki, Kanagawa 216-8511, Japan

E-mail: saji-q@ya2.so-net.ne.jp

Abbreviations: CI, confidence interval; NSCLC, non-small cell lung cancer; OS, overall survival; RFS, recurrence-free survival; SCLC, small cell lung cancer

Key words: lung adenocarcinoma, prognosis, minichromosome maintenance 2, prognostic factors, biomarkers prognostic factors (OS: HR=5.084, 95\% CI: 1.715-15.080, $\mathrm{P}=0.003$; RFS: HR=2.761, 95\% CI: 1.090-6.998, $\mathrm{P}=0.032$ ). Therefore, the findings of the present study demonstrated that MCM2 may serve as a potential biomarker and therapeutic target for lung adenocarcinoma.

\section{Introduction}

Minichromosome maintenance (MCM) proteins are DNA helicases essential for DNA replication and participate in eukaryotic DNA replication by binding to chromatin before the initiation of DNA replication from the early G1 phase to the $\mathrm{S}$ phase of the cell cycle (1). Hence, MCM protein deregulation has been linked to tumor formation, progression and malignant transformation. MCM2, a member of the MCM family (MCM2-MCM7) that comprises 904 amino acids and has a molecular mass of $102 \mathrm{kDa}$, has been shown to be a cell proliferation marker (2).

MCM proteins have been shown to promote cell proliferation in vitro and in vivo in several types of cancer, and MCM expression is implicated in cancer cell proliferation mainly because these proteins can enhance DNA replication. MCM2 and MCM7, in particular, are involved in various cellular functions in humans and other eukaryotes (3). MCM7 expression in the bronchial brushing of patients with non-small cell lung cancer (NSCLC) has been found to be associated with prognosis (4), whereas MCM2 is frequently expressed during premalignant lung cell proliferation and is reportedly a sensitive marker for the early detection of pulmonary malignant lesions. MCM expression has also been associated with higher cell proliferation in non-dysplastic squamous epithelium, malignant fibrous histiocytomas and endometrial carcinoma. Furthermore, MCM2 expression has been found to be associated with a higher mitotic index and worse survival in patients with breast cancer, colon cancer, adrenocortical carcinoma and gliomas (5-7).

We previously identified the molecular signatures for malignancy in small cell lung cancer (SCLC), which is characterized by highly aggressive clinical features and poor prognosis, and detected the following five tumor proliferation proteins involved in SCLC malignancy: MCM2, MCM4, 
MCM6, MCM7 and MutS homolog 2 (MSH2) (1). Hence, the aim of the present study was to investigate whether MCM2 expression is of clinical and prognostic value in patients who have undergone resection of lung adenocarcinoma.

\section{Materials and methods}

Patients. Between January 2009 and December 2010, 102 patients with lung adenocarcinoma underwent complete pulmonary resection at St. Marianna Medical University Hospital (Kanagawa, Japan). Complete pulmonary resection was defined as lobectomy or a more extensive lung resection with ipsilateral hilar and mediastinal lymph node dissection and no evidence of residual cancer, either macroscopically or microscopically. Patients who had received preoperative chemotherapy, radiotherapy, or both, were excluded.Ultimately, 73 patients with a final pathological diagnosis of lung adenocarcinoma measuring $\geq 10 \mathrm{~mm}$ were enrolled in the present study.

The following clinicopathological data were collected from the hospital charts of all patients: Age, sex, pathological $\mathrm{T}$ factor, histological type, surgical procedure(s), relapse type, EGFR mutation status, overall survival (OS) and recurrence-free survival (RFS). OS was defined as the time from the day of the surgery until the day of death from any cause; patients who remained alive at the end of the follow-up period were treated as censored cases. RFS was defined as the time from the day of surgery to the day of disease recurrence or death from any cause; patients who remained alive with no evidence of recurrence at the end of the follow-up period were treated as censored cases.

Preoperative evaluation included physical examination, blood examination, chest radiography and chest and abdominal CT, as well as brain CT or MRI and positron emission tomography (PET)-CT if clinically indicated. Staging and pathological findings for lung adenocarcinoma were based on the 7th TNM Classification for Lung and Pleural Tumors (8), the World Health Organization classification (9), and the International Association for the Study of Lung Cancer/American Thoracic Society/European Respiratory Society classification of lung adenocarcinoma (10).

Following pulmonary resection, all patients were followed up at our institute every 3 months during the first year 1 , every 6 months during years $2-5$ and annually thereafter as outpatients; the follow-up continued for $\geq 5$ years. The follow-up included physical examination, chest radiography and blood examination, including serum tumor markers such as carcinoembryonic antigen. Patients also routinely underwent chest and upper abdominal $\mathrm{CT}$ at every scheduled outpatient appointment. Brain MRI and/or PET-CT examinations were performed if any symptoms or signs of recurrence were detected. If metastasis was observed, the metastatic site was confirmed histologically or cytologically when clinically feasible. Additionally, EGFR-TKIs were administered to 11 patients with disease recurrence, including gefitinib in 10 cases, erlotinib in 4 cases, afatinib in 3 cases and osimertinib in 1 case.

Clinical samples were tested using cobas ${ }^{\circledR}$ EGFR Mutation Test version 2.0 (Roche Diagnostics) or the peptide nucleic acid-locked nucleic acid (PNA-LNA) PCR clamp method
(LSI Medience Corporation). Deletion mutations in exon 19 and point mutations in exon 18 or exon 21(L858R) were considered to be EGFR mutations in the present study.

MCM2 expression. All collected surgical specimens were fixed in $10 \%$ formalin for $24 \mathrm{~h}$ at room temperature and then embedded in paraffin. The representative samples were routinely stained with hematoxylin for $20 \mathrm{~min}$ at room temperature and eosin for $1 \mathrm{~min}$ at room temperature by experienced pathologists, followed by reviewing to confirm the inclusion of carcinoma cells. Next, the formalin-fixed, paraffin-embedded blocks were cut into serial 3- $\mu \mathrm{m}$ sections for immunohistochemistry (IHC). All assays were performed using the automated Histostainer 36 A immunostainer (Nichirei Biosciences Inc.) according to the manufacturer's instructions. In addition, the sections were incubated for $60 \mathrm{~min}$ at room temperature with anti-MCM2 monoclonal antibody (1:2,000; cat. no. ab4461; Abcam) and examined by IHC; specificity was confirmed by using large-cell neuroendocrine carcinoma as a positive control according to the expression data in the Human Protein Atlas database (https://www.proteinatlas.org/).

To evaluate MCM2 antibody immunoreactivity, five microscopic, high-power fields (magnification, $\mathrm{x} 400$ ) were randomly selected using a BX51 polarizing microscope (Olympus Corporation); each field was scored a positive rate calculated as the percentage of positive cells per total number of cells. Considering that MCM2 is expressed in the nucleus, the number of nucleus-positive cells was counted. Three independent evaluators, including a pathologist certified by the Japanese Society of Pathology, assessed the cells for immunoreactivity and calculated the average value. The expression levels of MCM2 were assessed using the labeling index, which was determined by counting the number of distinctly stained malignant cells, regardless of the staining intensity, divided by the total number of tumor cells.

Statistical analysis. The OS and PRS were estimated using the Kaplan-Meier method, and differences in survival rates were determined by log-rank analysis. Univariate analysis was performed among different groups. The $\chi^{2}$ test and Mann-Whitney $U$ test were used for analyzing the categorical variables and identifying differences between two groups, respectively. For multivariate analysis, the Cox proportional hazards model with significant factors identified by the univariate analysis was used to determine the association between survival and potential prognostic factors. All P-values were two-sided, and $\mathrm{P}<0.05$ was considered to indicate statistically significant differences.

All statistical data were analyzed using EZR (Saitama Medical Center, Jichi Medical University, Saitama, Japan), a graphical user interface for $\mathrm{R}$, and a modified version of $\mathrm{R}$ commander that adds statistical functions frequently used in biostatistics (R Foundation for Statistical Computing, Vienna, Austria).

\section{Results}

Association between patient characteristics and MCM2 expression. The baseline characteristics of the 73 patients and the association between MCM2 expression and 
Table I. Baseline characteristics of patients $(n=73)$ and association between MCM2 expression and clinicopathological factors.

\begin{tabular}{|c|c|c|c|c|}
\hline \multirow[b]{2}{*}{ Variables } & \multirow[b]{2}{*}{ No. of patients } & \multicolumn{2}{|c|}{ MCM2 expression ${ }^{\mathrm{b}}$} & \multirow[b]{2}{*}{ P-value } \\
\hline & & $\operatorname{High}(\mathrm{n})$ & Low (n) & \\
\hline Sex & & & & 0.557 \\
\hline Male & 36 & 20 & 16 & \\
\hline Female & 37 & 17 & 20 & \\
\hline Age, years (mean, 70; range, 33-84) & & & & 0.727 \\
\hline$\geq 70$ & 37 & 20 & 17 & \\
\hline$<70$ & 36 & 17 & 19 & \\
\hline Smoking status & & & & 0.564 \\
\hline Current or former & 40 & 22 & 18 & \\
\hline Never & 33 & 15 & 18 & \\
\hline Adenocarcinoma subtypes & & & & $0.017^{\mathrm{a}}$ \\
\hline In situ & 2 & 0 & 2 & \\
\hline Minimally invasive & 2 & 0 & 2 & \\
\hline Lepidic-predominant & 8 & 0 & 8 & \\
\hline Papillary-predominant & 19 & 10 & 9 & \\
\hline Acinar-predominant & 29 & 17 & 12 & \\
\hline Solid-predominant & 9 & 7 & 2 & \\
\hline Micropapillary-predominant & 3 & 2 & 1 & \\
\hline Pathological stage & & & & 0.078 \\
\hline pIAB & 53 & 23 & 30 & \\
\hline pII-III & 20 & 14 & 6 & \\
\hline $\mathrm{T}$ factor (mean diameter, $23 \mathrm{~mm}$; range, $10-74 \mathrm{~mm}$ ) & & & & 0.362 \\
\hline $\mathrm{T} 1$ & 45 & 21 & 24 & \\
\hline $\mathrm{T} 2$ & 23 & 12 & 11 & \\
\hline $\mathrm{T} 3-4$ & 5 & 4 & 1 & \\
\hline $\mathrm{N}$ factor & & & & $0.020^{\mathrm{a}}$ \\
\hline N0 & 56 & 25 & 31 & \\
\hline N1 & 4 & 1 & 3 & \\
\hline N2 & 13 & 11 & 2 & \\
\hline EGFR status & & & & 0.397 \\
\hline Positive & 33 & 16 & 17 & \\
\hline Negative & 35 & 17 & 18 & \\
\hline Unknown & 5 & 4 & 1 & \\
\hline Distant recurrence & & & & $0.024^{\mathrm{a}}$ \\
\hline Yes & 15 & 12 & 3 & \\
\hline No & 58 & 25 & 33 & \\
\hline
\end{tabular}

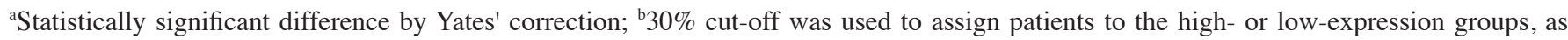
$\geq 30 \%$ MCM2 expression in patients with resected lung adenocarcinoma served as the full cut-off value in the survival analysis. MCM2, minichromosome maintenance 2 .

clinicopathological factors are presented in Table I. According to the IHC assessment of MCM2 expression in lung adenocarcinoma tissues (Fig. 1), 35 (48.0\%) of the 73 patients exhibited high MCM2 expression levels. High MCM2 expression was statistically significantly associated with lung adenocarcinoma subtypes $(\mathrm{P}=0.0051), \mathrm{N}$ factor $(\mathrm{P}=0.0117)$ and distant recurrence $(\mathrm{P}=0.0186)$. MCM2 is differentially expressed among different subtypes (lepidic-, acinar- and papillary-predominant) of lung adenocarcinoma, with the lowest expression levels observed in lepidic-predominant lung adenocarcinoma (Fig. 1D).

Survival analysis and prognostic factors. The median follow-up time was 69 months (range, 6-120 months). To investigate the prognostic impact of MCM2 expression in patients with resected lung adenocarcinoma, patients were 
Table II. Association between OS or RFS and MCM2 expression.

\begin{tabular}{|c|c|c|c|c|c|c|c|c|}
\hline \multicolumn{3}{|c|}{ MCM2 expression } & \multicolumn{3}{|c|}{ OS } & \multicolumn{3}{|c|}{ RFS } \\
\hline Positive (\%) & Positive (n) & Negative (n) & P-value & HR & $95 \%$ CI & P-value & HR & $95 \% \mathrm{CI}$ \\
\hline 15 & 60 & 13 & 0.237 & 2.399 & $0.562-10.240$ & 0.677 & 1.254 & $0.431-3.644$ \\
\hline 20 & 50 & 23 & $0.040^{\mathrm{a}}$ & 3.563 & $1.059-11.990$ & $0.035^{\mathrm{a}}$ & 3.143 & $1.082-9.130$ \\
\hline 25 & 46 & 27 & $0.012^{\mathrm{a}}$ & 4.702 & $1.397-15.830$ & $0.008^{\mathrm{a}}$ & 4.204 & $1.447-12.220$ \\
\hline 30 & 37 & 36 & $0.001^{\mathrm{a}}$ & 5.697 & $1.936-16.760$ & $0.003^{\mathrm{a}}$ & 3.745 & $1.568-8.944$ \\
\hline 35 & 31 & 42 & $0.001^{\mathrm{a}}$ & 4.672 & $1.840-11.870$ & $0.009^{\mathrm{a}}$ & 2.873 & $1.299-6.356$ \\
\hline 40 & 26 & 47 & $0.002^{\mathrm{a}}$ & 4.008 & $1.697-9.465$ & $0.010^{\mathrm{a}}$ & 2.784 & $1.283-6.043$ \\
\hline
\end{tabular}

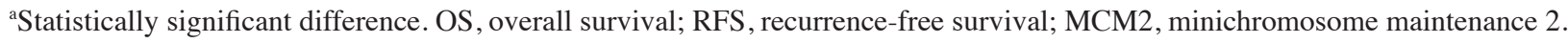
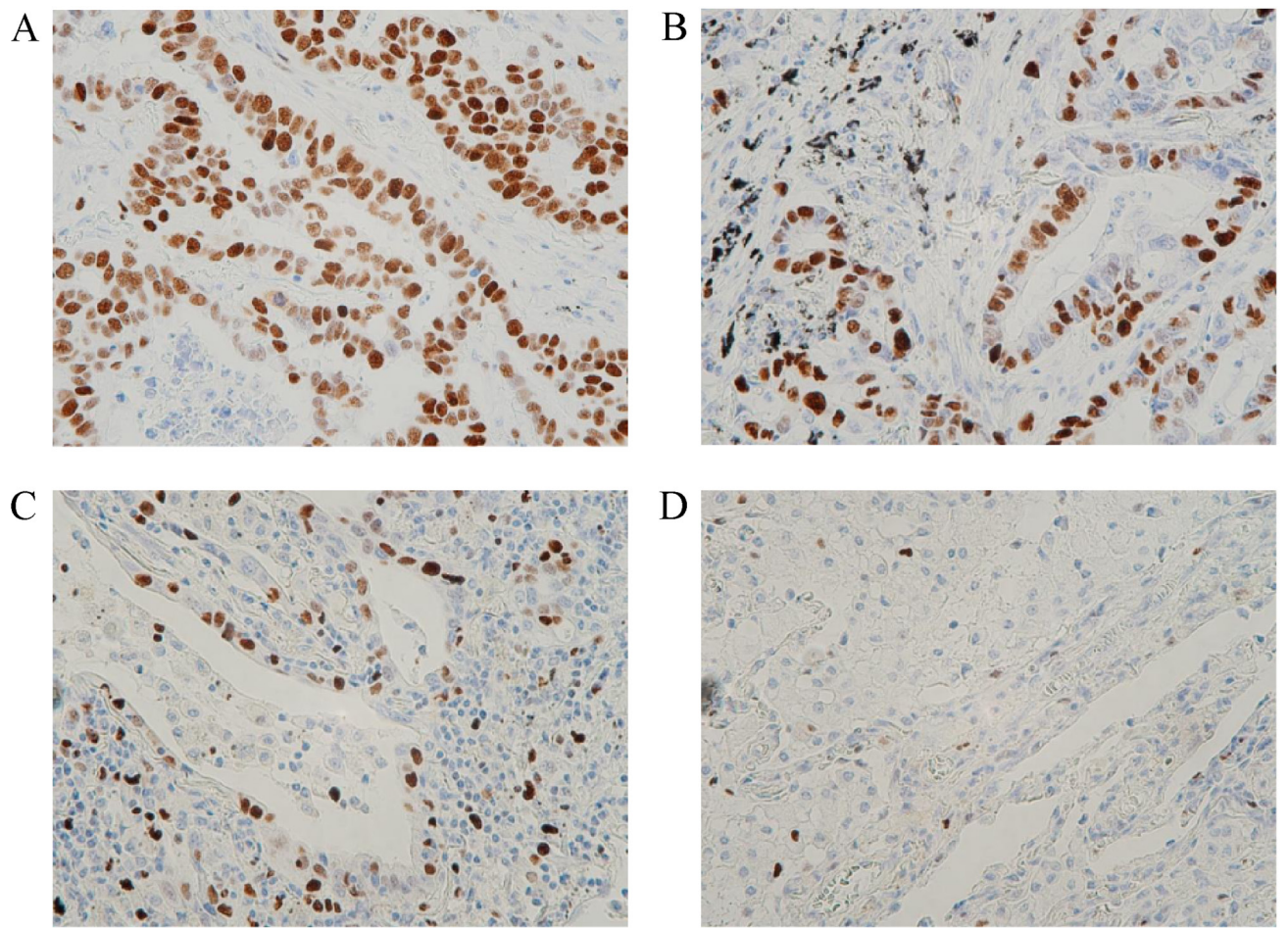

Figure 1. Expression status of MCM2 in lung adenocarcinoma tissue samples. (A-D) Representative immunohistochemistry microphotographs of MCM2 with (A) $90 \%$, (B) $54 \%$, (C) $33 \%$ and (D) $9 \%$ expression in lung adenocarcinoma tissues. MCM2, minichromosome maintenance 2. Magnification, x400.

grouped according to MCM2 expression (\%) as follows: Groups $1(<15$ vs. $\geq 15), 2(<20$ vs. $\geq 20), 3(<25$ vs. $\geq 25)$, 4 ( $<30$ vs. $\geq 30), 5$ ( $<35$ vs. $\geq 35$ ) and $6(<40$ vs. $\geq 40)$. Group 4 exhibited the most significant difference in MCM2 expression in terms of the OS. Therefore, $\geq 30 \%$ MCM2 expression in patients with resected lung adenocarcinoma served as the cutoff value in survival analysis. The results of the comparisons among groups are summarized in Table II.

Patients with high MCM2 expression had significantly worse 5-year OS and 5-year RFS compared with those with low MCM2 expression (OS: 54.1 vs. $86.3 \%$, respectively, $\mathrm{P}<0.001$, Fig. 2 A; RFS: 53.9 vs. $81.7 \%$, respectively, $\mathrm{P}=0.001$, Fig. 2B). Of the 11 patients with stage IB lung adenocarcinoma, $2(18.2 \%)$ received postoperative adjuvant therapy with oral uracil-tegafur. Furthermore, $10(50.0 \%)$ of 20 patients with stage II-III lung adenocarcinoma received intravenous platinum doublet-based chemotherapy. However, 27 patients relapsed, of whom 17, 7 and 1 patients received standard anticancer therapy (according to the guidelines published by the Japan Lung Cancer Society in 2016; https://www.haigan.gr.jp/), EGFR-tyrosine kinase inhibitors and immune checkpoint inhibitors, respectively. In addition, 16 (59.3\%), 8 (29.6\%) and $4(14.8 \%)$ patients received first-, second- and third-line therapies, respectively, but 6 (22.2\%) did not receive treatment upon disease recurrence.

As mentioned above, univariate and multivariate survival analyses were performed to identify the potential prognostic factors for OS and RFS (Table III). Univariate analysis revealed that the significant prognostic factors for the OS of lung adenocarcinoma included pathological stage and MCM2 expression $(\mathrm{P}<0.001$ and $\mathrm{P}<0.002$, respectively), whereas those for the RFS included pathological stage, EGFR mutation 
Table III. Univariate and multivariate survival analyses in patients with lung adenocarcinoma.

\begin{tabular}{|c|c|c|c|c|c|c|}
\hline \multirow[b]{2}{*}{ Variables } & \multicolumn{3}{|c|}{ Univariate analysis } & \multicolumn{3}{|c|}{ Multivariate analysis } \\
\hline & P-value & HR & $95 \%$ CI & P-value & Risk ratio & $95 \% \mathrm{CI}$ \\
\hline \multicolumn{7}{|l|}{ OS } \\
\hline Age $\geq 70$ years $($ vs. $<70)$ & 0.089 & 2.114 & $0.893-5.002$ & - & - & - \\
\hline Male sex (vs. female) & 0.247 & 1.641 & $0.710-3.793$ & - & - & - \\
\hline Smoking (vs. no) & 0.909 & 0.960 & $0.480-1.923$ & & & \\
\hline pStage I (vs. II-III) & $<0.001^{\mathrm{a}}$ & 7.249 & $3.054-17.210$ & $<0.001^{\mathrm{a}}$ & 6.688 & $2.783-16.070$ \\
\hline EGFR mutation-positive (vs. negative) & 0.8791 & 1.07 & $0.445-2.574$ & - & - & - \\
\hline MCM2 high (vs. low) ${ }^{\mathrm{b}}$ & $0.002^{\mathrm{a}}$ & 5.697 & $1.936-16.760$ & $0.003^{\mathrm{a}}$ & 5.084 & $1.715-15.080$ \\
\hline \multicolumn{7}{|l|}{ RFS } \\
\hline Age $\geq 70$ years $($ vs. $<70)$ & 0.300 & 1.514 & $0.691-3.318$ & - & - & - \\
\hline Male sex (vs. female) & 0.992 & 1.004 & $0.472-2.137$ & - & - & - \\
\hline Smoking (vs. no) & 0.550 & 0.824 & $0.436-1.556$ & & & \\
\hline pStage I (vs. II-III) & $<0.001^{\mathrm{a}}$ & 6.728 & $3.017-15.000$ & $0.001^{\mathrm{a}}$ & 4.115 & $1.731-9.778$ \\
\hline EGFR mutation-positive (vs. negative) & $0.034^{\mathrm{a}}$ & 2.491 & $1.074-5.778$ & 0.055 & 2.304 & $0.981-5.409$ \\
\hline MCM2 high (vs. low) ${ }^{\mathrm{b}}$ & $0.003^{\mathrm{a}}$ & 3.745 & $1.568-8.944$ & $0.032^{\mathrm{a}}$ & 2.761 & $1.090-6.998$ \\
\hline
\end{tabular}

${ }^{\text {aS }}$ tatistically significant difference; ${ }^{b} 30 \%$ cut-off was used to assign patients to the high- or low-expression groups, as $\geq 30 \%$ MCM2 expression in patients with resected lung adenocarcinoma served as the full cut-off value in the survival analysis. OS, overall survival; MCM2, minichromosome maintenance 2; RFS, recurrence-free survival.

A

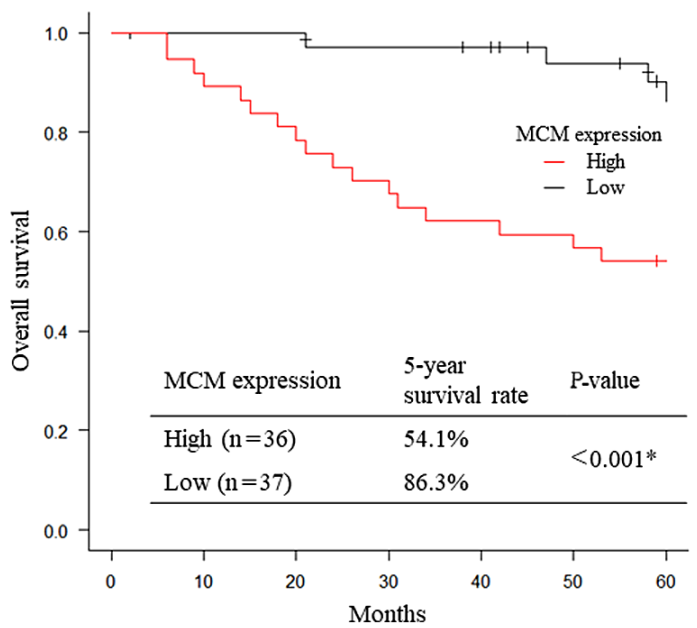

B

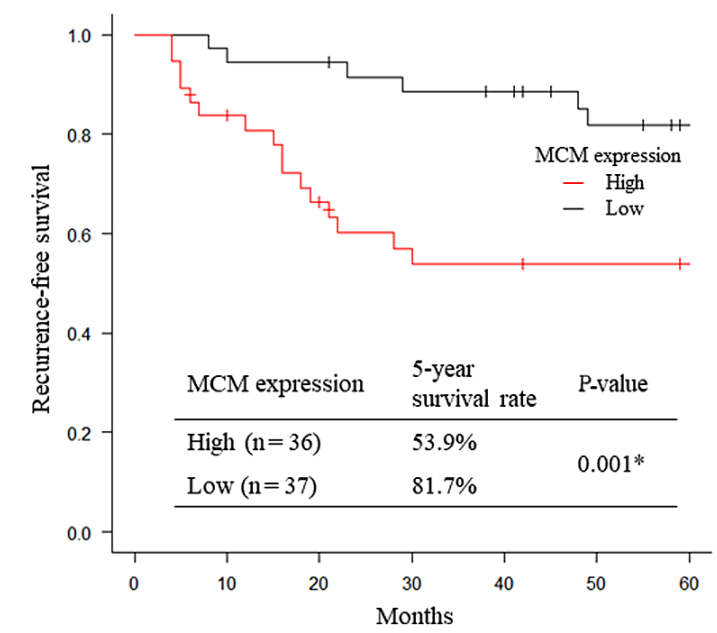

Figure 2. Association of MCM2 with OS and RFS in patients with adenocarcinoma. Kaplan-Meier curves showing the association between the MCM2 expression status in (A) OS and (B) RFS. All P-values were determined by the log-rank test and are shown in the graph. *Statistically significant difference OS, overall survival; RFS recurrence-free survival; MCM2, minichromosome maintenance 2.

status and MCM2 expression $(\mathrm{P}<0.001, \mathrm{P}<0.034$ and $\mathrm{P}<0.003$, respectively). On multivariate survival analysis, high MCM2 expression (pathological stage II-III) was found to be a strong prognostic factor and was independent of and superior to the EGFR mutation status (OS: HR=5.084, 95\% CI: 1.715-15.080, $\mathrm{P}=0.003$; RFS: $\mathrm{HR}=2.761,95 \%$ CI: 1.090-6.998, $\mathrm{P}=0.032$ ).

\section{Discussion}

MCM proteins serve as biological markers of dysplasia and malignancy (11). Although MCM proteins promote cancer cell proliferation, MCM expression is a poor prognostic marker in several types of cancer, such as breast cancer, renal cell carcinoma, prostate cancer, colorectal cancer, lung cancer, glioma and cervical cancer (4-6,12-15). According to the protein-protein interaction network analysis of 201 proteins as previously reported (1), SCLC is functionally characterized by molecular pathway activation for spliceosome, RNA transport, and DNA replication and the cell cycle. In particular, the following 11 proteins have been identified as SCLC-specific proteins: MCM2, MCM4, MCM6, MCM7 and MSH2 for tumor proliferation; regulator of chromosome condensation 2, 
coronin-1C, chromodomain helicase DNA-binding protein 4 and importin 9 for metastasis; and phosphoglycerate dehydrogenase and thymidine phosphorylase for cancer metabolism. For both SCLC and NSCLC, MCM2 is a potentially poor prognostic factor according to an online Kaplan-Meier survival analysis (1). Therefore, the present study was focused on MCM2 expression in resected NSCLC tissues and performed further survival analysis.

In our analysis of the correlation between MCM2 expression and clinicopathological characteristics of patients with resected lung adenocarcinoma, those with a history of smoking, male sex, or late-stage cancer exhibited significantly high MCM2 expression levels. Similarly, MCM2 has been found to be significantly associated with tumor stage in patients with lung cancer (16), and high MCM2 expression in NSCLC is more frequently observed among elderly patients and patients with late-stage disease (17). Overall, high MCM2 expression is linked to aggressive progression in the majority of cancer types.

Moreover, multivariate analysis of the OS showed that MCM2 expression may serve a biomarker and an independent factor of unfavorable prognosis, consistent with previous studies $(17,18)$. As regards RSF, high MCM2 expression in lung adenocarcinoma was shown to be associated with early metastasis recurrence (Fig. 2B), particularly distant metastasis (Table I). These results provide useful information for thoracic surgeons and medical oncologists and for postoperative follow-up management.

MCM proteins, which are highly conserved helicases and key regulatory components of eukaryotic DNA replication, are overexpressed in several cancer types, and are therefore considered as important targets of chemotherapy. The potential of MCMs as a therapeutic target has been previously reported. Suppression of MCM complexes was found to sensitize pancreatic cancer cells to cytotoxic chemotherapy agents (gemcitabine and 5-FU) and enhance treatment efficacy (19). MCM7 was found to play an important role in cell proliferation by promoting quiescence-reactivated proliferation and paclitaxel resistance (20). In addition, MCM2 may serve as a functional target for long non-coding RNAs and microRNAs in regulating tumor cell proliferation, migration and apoptosis $(21,22)$. Moreover, the anti-hyperlipidemic agent lovastatin, as an inhibitor of 3-hydroxy-3-methylglutaryl coenzyme A has demonstrated antitumor activity by silencing MCM2, triggering G1/S arrest in NSCLC cells (23). However, further research into targeting MCM is required.

There were certain limitations to the present study. First, this study was retrospective, rather than prospective or multicenter; therefore, bias might exist. Second, the sample size was small and possibly inadequate for obtaining reliable results. Third, the postoperative observation period was relatively brief. Further studies with a larger cohort are necessary to confirm our results. Finally, no data on CD56 positivity in the tumor cells were assessed in this study to evaluate neuroendocrine tumor characteristics in association with high MCM2 expression.

In conclusion, MCM2 overexpression in patients with lung adenocarcinoma appears to be an independent factor for an unfavorable prognosis in terms of OS and RFS. Therefore, MCM2 may represent a potential biomarker and therapeutic target for such patients.

\section{Acknowledgements}

Not applicable.

\section{Funding}

The present study was supported by a Grant-in-Aid for Scientific Research, Japan Society for the Promotion of Science (grant no. 24592104), Ministry of Education, Culture, Sports, Science and Technology, Japan.

\section{Availability of data and materials}

The datasets used and/or analyzed during the current study are available from the corresponding author on reasonable request.

\section{Authors' contributions}

HSakai, first author, and HSaji, corresponding author, served as the principal authors, performed data acquisition and had full access to all the data in the study, and are responsible for confirming the integrity and authenticity of the data and the accuracy of the data analysis. HSakai and HSaji contributed to study conception and design, coordination of the study and revised the article for important intellectual content. HK, TM, $\mathrm{HM}, \mathrm{NF}, \mathrm{KK}$ and $\mathrm{KO}$ enrolled patients and contributed to preparing the manuscript. MC, JK, KF, TN and $\mathrm{HN}$ assessed the cells for immunoreactivity and contributed to preparing the manuscript. All the authors have read and approved the final version of the manuscript to be published.

\section{Ethics approval and consent to participate}

The Institutional Review Board of the St. Marianna Medical University in Kanagawa, Japan approved this study (accession no. 1461). Prior to the study, written informed consent was obtained from all participants. All patient data remained confidential throughout this research.

\section{Patient consent for publication}

Not applicable.

\section{Competing interests}

All authors declare that they have no competing interests.

\section{References}

1. Fujii K, Miyata Y, Takahashi I, Koizumi H, Saji H, Hoshikawa M, Takagi M, Nishimura T and Nakamura H: Differential Proteomic Analysis between Small Cell Lung Carcinoma (SCLC) and Pulmonary Carcinoid Tumors Reveals Molecular Signatures for Malignancy in Lung Cancer. Proteomics Clin Appl 12: e1800015, 2018.

2. Bell SP and Dutta A: DNA replication in eukaryotic cells. Annu Rev Biochem 71: 333-374, 2002.

3. Neves H and Kwok HF: In sickness and in health: The many roles of the minichromosome maintenance proteins. Biochim Biophys Acta Rev Cancer 1868: 295-308, 2017

4. Liu YZ, Jiang YY, Hao JJ, Lu SS, Zhang TT, Shang L, Cao J, Song X, Wang BS, Cai Y, et al: Prognostic significance of MCM7 expression in the bronchial brushings of patients with non-small cell lung cancer (NSCLC). Lung Cancer 77: 176-182, 2012. 
5. Gonzalez MA, Pinder SE, Callagy G, Vowler SL, Morris LS, Bird K, Bell JA, Laskey RA and Coleman N: Minichromosome maintenance protein 2 is a strong independent prognostic marker in breast cancer. J Clin Oncol 21: 4306-4313, 2003.

6. Kaur G, Balasubramaniam SD, Lee YJ, Balakrishnan V and Oon CE: Minichromosome Maintenance Complex (MCM) Genes Profiling and MCM2 Protein Expression in Cervical Cancer Development. Asian Pac J Cancer Prev 20: 3043-3049, 2019.

7. Nasri Nasrabadi P, Nayeri Z, Gharib E, Salmanipour R Masoomi F, Mahjoubi F and Zomorodipour A: Establishment of a CALU, AURKA, and MCM2 gene panel for discrimination of metastasis from primary colon and lung cancers. PLoS One 15: e0233717, 2020.

8. Goldstraw P, Groome P: Lung and pleural tumours. In: TNM Classification of Malignant Tumours. 7th edition. Sobin, LH Gospodarowicz MK and Wittekind C (eds). Wiley-Blackwell, Chichester, West Sussex, pp 136-150, 2009.

9. Travis W, Brambilla E and Müller-Hermelink HK (eds): World Health Organization Classification of Tumours: Pathology and Genetics of Tumors of the Lung, Pleura, Thymus and Heart. IARC Press, Lyon, 2004.

10. Travis WD, Brambilla E, Noguchi M, Nicholson AG, Geisinger KR, Yatabe Y, Beer DG, Powell CA, Riely GJ, Van Schil PE, et al: International association for the study of lung cancer/american thoracic society/european respiratory society international multidisciplinary classification of lung adenocarcinoma. J Thorac Oncol 6: 244-285, 2011.

11. Freeman A, Morris LS, Mills AD, Stoeber K, Laskey RA, Williams GH and Coleman N: Minichromosome maintenance proteins as biological markers of dysplasia and malignancy. Clin Cancer Res 5: 2121-2132, 1999.

12. Dudderidge TJ, Stoeber K, Loddo M, Atkinson G, Fanshawe T, Griffiths DF and Williams GH: Mcm2, Geminin, and KI67 define proliferative state and are prognostic markers in renal cell carcinoma. Clin Cancer Res 11: 2510-2517, 2005.

13. Dudderidge TJ, McCracken SR, Loddo M, Fanshawe TR, Kelly JD, Neal DE, Leung HY, Williams GH and Stoeber K: Mitogenic growth signalling, DNA replication licensing, and survival are linked in prostate cancer. Br J Cancer 96: 1384-1393, 2007.
14. Nishihara K, Shomori K, Fujioka S, Tokuyasu N, Inaba A, Osaki M, Ogawa T and Ito H: Minichromosome maintenance protein 7 in colorectal cancer: Implication of prognostic significance. Int J Oncol 33: 245-251, 2008.

15. Hua C, Zhao G, Li Y and Bie L: Minichromosome Maintenance (MCM) Family as potential diagnostic and prognostic tumor markers for human gliomas. BMC Cancer 14: 526, 2014.

16. Veena VS, George PS, Rajan K, Chandramohan K, Jayasree K and Sujathan K: Immunocytochemistry on Sputum Samples Predicts Prognosis of Lung Cancer. J Cytol 36: 38-43, 2019.

17. Liu YZ, Wang BS, Jiang YY, Cao J, Hao JJ, Zhang Y, Xu X, Cai Y and Wang MR: MCMs expression in lung cancer: Implication of prognostic significance. J Cancer 8: 3641-3647, 2017.

18. Ramnath N, Hernandez FJ, Tan DF, Huberman JA, Natarajan N, Beck AF, Hyland A, Todorov IT, Brooks JS and Bepler G: MCM2 is an independent predictor of survival in patients with non-small-cell lung cancer. J Clin Oncol 19: 4259-4266, 2001.

19. Bryant VL, Elias RM, McCarthy SM, Yeatman TJ and Alexandrow MG: Suppression of Reserve MCM Complexes Chemosensitizes to Gemcitabine and 5-Fluorouracil. Mol Cancer Res 13: 1296-1305, 2015.

20. Jia M, Zheng D, Wang X, Zhang Y, Chen S, Cai X, Mo L, $\mathrm{Hu} \mathrm{Z}$, Li H, Zhou Z, et al: Cancer Cell enters reversible quiescence through Intracellular Acidification to resist Paclitaxel Cytotoxicity. Int J Med Sci 17: 1652-1664, 2020.

21. Jin Y, Xiong A, Zhang Z, Li S, Huang H, Yu TT, Cao X and Cheng SY: MicroRNA-31 suppresses medulloblastoma cell growth by inhibiting DNA replication through minichromosome maintenance 2. Oncotarget 5: 4821-4833, 2014.

22. Liu F, Yuan JH, Huang JF, Yang F, Wang TT, Ma JZ, Zhang L, Zhou CC, Wang F, Yu J, et al: Long noncoding RNA FTX inhibits hepatocellular carcinoma proliferation and metastasis by binding MCM2 and miR-374a. Oncogene 35: 5422-5434, 2016.

23. Zhang X, Teng Y, Yang F, Wang M, Hong X, Ye LG, Gao YN and Chen GY: MCM2 is a therapeutic target of lovastatin in human non-small cell lung carcinomas. Oncol Rep 33: 2599-2605, 2015. 